\title{
Glomerular Filtration Rate and/or Ratio of Urine Albumin to Creatinine as Markers for Diabetic Retinopathy: A Ten-Year Follow-Up Study
}

\author{
Pedro Romero-Aroca $\mathbb{D}^{1},{ }^{1}$ Marc Baget-Bernaldiz, ${ }^{1}$ Raul Navarro-Gil, ${ }^{1}$ \\ Antonio Moreno-Ribas $\mathbb{D}^{2},{ }^{2}$ Aida Valls-Mateu $\left(\mathbb{D},{ }^{2}\right.$ Ramon Sagarra-Alamo, ${ }^{3}$ \\ Joan F. Barrot-De La Puente, ${ }^{4}$ and Xavier Mundet-Tuduri ${ }^{5}$ \\ ${ }^{1}$ Ophthalmology Service, University Hospital Sant Joan, Institut de Investigacio Sanitaria Pere Virgili (IISPV), Universitat Rovira \& \\ Virgili, Reus, Spain \\ ${ }^{2}$ Department of Computer Engineering and Mathematics, Universitat Rovira \& Virgili, Reus, Spain \\ ${ }^{3}$ Health Care Area Reus-Priorat, Institut Catala de la Salut (ICS), Institut de Investigació Sanitària Pere Virgili (IISPV), Universitat \\ Rovira \& Virgili, Reus, Spain \\ ${ }^{4}$ Health Care Area Jordi Nadal de Salt (ICS), Unitat de Suport a la Recerca Barcelona Ciutat, Institut Universitari d'Investigacio en \\ Atencio Primaria Jordi Gol (IDIAP Jordi Gol), Barcelona, Spain \\ ${ }^{5}$ Unitat de Suport a la Recerca Barcelona Ciutat, Institut Universitari d'Investigacio en Atencio Primaria Jordi Gol (IDIAP Jordi Gol), \\ Universitat Autonoma de Barcelona, Bellaterra, Spain
}

Correspondence should be addressed to Pedro Romero-Aroca; romeropere@gmail.com

Received 13 November 2017; Revised 20 December 2017; Accepted 26 December 2017; Published 26 February 2018

Academic Editor: Marco Songini

Copyright (c) 2018 Pedro Romero-Aroca et al. This is an open access article distributed under the Creative Commons Attribution License, which permits unrestricted use, distribution, and reproduction in any medium, provided the original work is properly cited.

\begin{abstract}
Aims. To determine the relationship between diabetic nephropathy and diabetic retinopathy on a population of type 2 diabetes mellitus patients. Methods. A prospective ten-year follow-up population-based study. We determined differences between estimated glomerular filtration rate (eGFR) using the chronic kidney disease epidemiology collaboration equation and urine albumin to creatinine ratio. Results. Annual incidence of any-DR was $8.21 \pm 0.60 \%(7.06 \%-8.92 \%)$, sight-threatening diabetic retinopathy (STDR) was $2.65 \pm 0.14 \%(2.48 \%-2.88 \%)$, and diabetic macular edema (DME) was $2.21 \pm 0.18 \%(2 \%-2.49 \%)$. Renal study results were as follows: UACR $>30 \mathrm{mg} / \mathrm{g}$ had an annual incidence of $7.02 \pm 0.05 \%(6.97 \%-7.09 \%)$, eGFR $<60 \mathrm{ml} / \mathrm{min} /$ $1.73 \mathrm{~m}^{2}$ incidence was $5.89 \pm 0.12 \%(5.70 \%-6.13 \%)$. Cox's proportional regression analysis of DR incidence shows that renal function studied by eGFR $<60 \mathrm{ml} / \mathrm{min} / 1.73 \mathrm{~m}^{2}$ was less significant $(p=0.04, \mathrm{HR} 1.223,1.098-1.201)$ than UACR $\geq 300 \mathrm{mg} / \mathrm{g}$ $(p<0.001$, HR $1.485,1.103-1.548)$. The study of STDR shows that $e$ GFR $<60 \mathrm{ml} / \mathrm{min} / 1.73 \mathrm{~m}^{2}$ was significant $(p=0.02$, HR $1.890,1.267-2.820)$, UACR $\geq 300 \mathrm{mg} / \mathrm{g}(p<0.001$, HR $2.448,1.595-3.757)$, and DME shows that eGFR $<60 \mathrm{ml} / \mathrm{min} / 1.73 \mathrm{~m}{ }^{2} \mathrm{was}$ significant $(p=0.02$, HR $1.920,1.287-2.864)$ and UACR $\geq 300 \mathrm{mg} / \mathrm{g}(p<0.001$, HR 2.432, 1.584-3.732). Conclusions. The UACR has a better association with diabetic retinopathy than the eGFR, although both are important risk factors for diabetic retinopathy.
\end{abstract}

\section{Introduction}

Diabetic nephropathy (DN) and retinopathy (DR) are microvascular complications of diabetes mellitus which share risk factors, such as poor glycemia control and systolic hypertension. Their relationship has been the focus of our previous studies, where we demonstrate good positive relationship of microalbuminuria and macroalbuminuria in type $1 \mathrm{DM}$ [1-3], despite in type $2 \mathrm{DM}$ only macroalbuminuria was a significant risk factor in DR development [3].

The presence of diabetic retinopathy (DR) is easy to establish through observable retinal lesions. However, diabetic renal lesion is more difficult to diagnose. Nondiabetic nephropathy has a prevalence in DM patients that varies 
from different studies $[4,5]$ and difficult diagnosis of diabetic nephropathy. Diabetic retinopathy is present in T1DM with diabetic nephropathy [6]; on the contrary, type 2DM patients can develop DN without diabetic retinopathy [7].

Also, current clinical guidelines differ, such as KDIGO (Kidney Diseases: Improving Global Outcomes), who defines chronic renal diseases as the presence of an estimated glomerular filtration rate inferior to $60 \mathrm{ml} / \mathrm{min} / 1.73 \mathrm{~m}^{2}$ or renal lesion that can be demonstrated from histological biopsy or by the ratio of urine albumin to creatinine (UACR) [8].

The recent introduction of estimated glomerular filtration rate (eGFR) has become an easy method for studying renal function, determined from serum creatinine, age, sex, and race [9]. At present, we have two major formulae, the equation of chronic kidney disease-epidemiology collaboration (CKD-EPI) [10] and the modification of diet in renal disease (MDRD-4 or MDRD-IDMS) [11]. Both can help us to determine renal function by a simple blood sample measure. The CKD-EPI equation is more accurate, especially with glomerular filtrate between 60 and $90 \mathrm{ml} / \mathrm{min} / 1.73 \mathrm{~m}^{2}$ [12].

As we have previously published studies on DR incidence and its risk factors using data collected since 2007 from our screening programme of 15,811 Caucasian, type $2 \mathrm{DM}$ patients [13], in the present study, we have the aim to determine whether there is a relationship between diabetic nephropathy and incidence of diabetic retinopathy in type 2 DM patients.

\section{Materials and Methods}

2.1. Setting. The reference population in our health care area (HCA) is 247,174 inhabitants. The current number of DM patients registered in our HCA is 18,528 .

2.2. Design and Sample. This is a prospective, populationbased study of 15,811 Caucasian, T2DM patients from data collected between 1st January 2007 and 31st December 2016, with a mean follow-up of $3.45 \pm 1.12$ times for each patient over the ten years. This includes $85.33 \%$ of T2DM patients of our HCA; the rest of the patients did not attend the screening, or they were lost during the study. Patients have been screened in our nonmydriatic fundus camera units (NMCU).

2.3. Power of the Study. Our epidemiologist evaluated the T2DM sample and estimated the accuracy of $95 \%$ with a $\pm 3 \%$ increase in risk.

2.4. Method. Screening for DR was carried out with one $45^{\circ}$ field retinograph, centred on the fovea. If DR was evident, another 2 retinographs of $45^{\circ}$ were taken according to EURODIAB guidelines. The complete method is described elsewhere $[14,15]$.

In the present study, DR is thus classified as (i) no$\mathrm{DR}=$ no diabetic retinopathy, (ii) any-DR = level 20 to 35 of the ETDRS, and (iii) STDR=level 43 or worse as defined by the ETDRS. The term diabetic macular edema (DME) includes extrafoveal and/or clinically significant macular edema (CSMO) according to the ETDRS classification [16].

Measures of renal diabetes disease were determined by (i) Serum creatinine, determined by molecular absorption spectrometry,

(ii) Estimated glomerular filtration rate (eGFR), calculated from plasma creatinine using chronic kidney disease epidemiology collaboration equation (CKDEPI equation):

(1) For women

(a) creatinine $<0.7 \mathrm{mg} / \mathrm{dl}$ eGFR $=144 \times($ creatinine $/ 0.7)^{-0.329} \times(0.993)^{\text {age }}$

(b) creatinine $>0.7 \mathrm{mg} / \mathrm{dl}$ eGFR $=144 \times($ creatinine/0.7 $)^{-1.209} \times(0.993)^{\text {age }}$

(2) For men

(a) creatinine $>0.9 \mathrm{mg} / \mathrm{dl}$ eGFR $=141 \times($ creatinine $/ 0.9)^{-1.209} \times(0.993)^{\text {age }}$

Gradation was expressed in $\mathrm{ml} / \mathrm{min} / 1.73 \mathrm{~m}^{2}$ and defined as normal $=e G F R>90$, mildly diminishe$\mathrm{d}=\mathrm{eGFR}$ 60-89, moderately diminished $=\mathrm{eGFR}$ 45-59, moderate-severely diminished $=$ eGFR 3044 , and severely diminished $=e G F R<30$.

(iii) Ratio of urine albumin to creatinine (UACR). UACR was collected from urine samples for measurement of albumin and creatinine. Albumin was measured in $\mathrm{mg} / \mathrm{l}$ and creatinine in $\mathrm{mmol} / \mathrm{l}$. The concentration ratio of urine to creatinine expressed in $\mathrm{mg} / \mathrm{g}$ was used to estimate the total daily albumin excretion.

UACR was classified as normoalbuminuria $=$ UACR $<30 \mathrm{mg} / \mathrm{g}$, microalbuminuria as UACR 30 $299 \mathrm{mg} / \mathrm{g}$, and macroalbuminuria as UACR $\geq 300 \mathrm{mg} / \mathrm{g}$.

The diagnosis of diabetic nephropathy was made by family physicians or endocrinologists, and according to the diagnosis, we use two different definitions of diabetic renal diseases:

(a) Chronic kidney disease is defined as UACR $\geq 30 \mathrm{mg} / \mathrm{g}$ or $\mathrm{eGFR}<60 \mathrm{ml} / \mathrm{min} / 1.73 \mathrm{~m}^{2}$.

(b) Renal failure is defined as UACR $\geq 300 \mathrm{mg} / \mathrm{g}$ and $\mathrm{eGFR}<30 \mathrm{ml} / \mathrm{min} / 1.73 \mathrm{~m}^{2}$.

At the end of the study in January 2017, all electronic databases of patients were screened again to confirm the number of patients with DR and if any new patients had not previously been diagnosed.

2.5. Inclusion Criteria. Patients with all T2DM were screened in our primary HCA.

2.6. Exclusion Criteria. Patients with other specific types of diabetes and patients with gestational DM were excluded.

We followed our methods published by RomeroAroca et al. [17]. 
2.7. Ethical Adherence. The study was carried out with the approval of the local ethics committee (approval number 13-01-31/proj6) and in accordance with revised guidelines of the Declaration of Helsinki. The study was approved and supported by Instituto de Salud Carlos III (IISCIII), Spain (FI12/01535, June 2013, and FI15/01150, July 15), and FEDER fundus.

2.8. Statistical Methods. The epidemiological risk factors included were as follows: current age, age at DM diagnosis, gender, duration and treatment of DM, arterial hypertension, levels of glycosylated haemoglobin $\left(\mathrm{HbA}_{1 \mathrm{c}}\right)$, triglycerides, cholesterol fractions, and mentioned renal disease measures.

Incidence was measured for each year of the study using the following formula: patients with DR/all patients screened.

The ten-year sum incidence was calculated as number of patients with DR over 10 years/subjects at risk.

Data evaluation and analysis was carried out using SPSS 22.0 statistical software package, and $p<0.05$ was considered to indicate statistical significance.

Descriptive statistical analysis of quantitative data was made by determining mean, standard deviation, minimum and maximum values, and the $95 \%$ confidence interval. For qualitative data, we used the analysis of frequency and percentage in each category. Differences were examined using the two-tailed Student $t$-tests to compare two variables or using one-way ANOVA analysis of variance if we were comparing more than two variables. Inferential analysis for qualitative data was made by chi-squared table and by the Fisher test for quantitative data.

Survival analysis was carried out using the following:

(i) The Kaplan-Meier curve measured the accumulated risk of developing DR (in each of three forms: anyDR, STDR, and DME) in patients with renal failure using UACR $\geq 300 \mathrm{mg} / \mathrm{g}$ and using eGFR $<30 \mathrm{ml} /$ $\min / 1.73 \mathrm{~m}^{2}$.

(ii) And the Cox proportional hazards model was used in order to evaluate survival curves considering other variables that may affect survival as age, sex, HbAlc, arterial hypertension, and DM treatment.

In Cox's survival analysis, we also applied four models:

(1) Without renal status inclusion; no eGFR nor UACR included

(2) Including eGFR $<60 \mathrm{ml} / \mathrm{min} / 1.73 \mathrm{~m}^{2}$ as variable

(3) Including $U A C R \geq 300 \mathrm{mg} / \mathrm{g}$ as variable

(4) Including eGFR $<60 \mathrm{ml} / \mathrm{min} / 1.73 \mathrm{~m}^{2}$ and $\mathrm{UACR} \geq$ $300 \mathrm{mg} / \mathrm{g}$ as variable

\section{Results}

3.1. Demographic Variables of Sample Size. In the ten-year follow-up (1 January 2007 to 31 December 2016), a total of 15,811 T2DM patients were screened (Table 1), which represents $85.33 \%$ of the total T2DM patients registered $(18,528)$ in our health care areas (HCAs), with a mean follow-up of $3.45 \pm 1.12$ times for each patient over the ten years.

The whole sample included more males (56.13\%), which does in fact reflect the prevalence of diabetes in the population as a whole. The mean current age was $63.91 \pm 11.85$ years and DM duration was $8.36 \pm 6.64$ years. Mean $\mathrm{HbA1c}$ values were $7.41 \pm 1.45 \%$ (3.9-15.8). Excluding differences in age, men are more frequently being significant at $p<0.001$.

Mean age of patients with any-DR was $63.91 \pm 11.85$ years, patients with STDR were $64.05 \pm 12.27$ years, and patients with DME were $64.36 \pm 12.84$ years.

3.2. Study of Incidence of Diabetic Retinopathy. A total of 4466 patients with T2DM developed any-DR (28.24\%), with a mean annual incidence of $8.21 \pm 0.60 \%$ (7.06\%$8.92 \%$ ) (Table 2). STDR in T2DM was developed in 1451 patients $(9.17 \%)$ with an annual incidence of $2.65 \pm 0.14 \%$ (2.48\%-2.88\%). DME in T2DM was developed in 1214 patients $(7.67 \%)$ with an annual incidence of $2.21 \pm 0.18 \%$ $(2 \%-2.49 \%)$.

3.3. Study of Incidence of Nephropathy. A total of 3767 patients $(23.82 \%)$ with T2DM had UACR $>30 \mathrm{mg} / \mathrm{g}$ with a mean annual incidence of $7.02 \pm 0.05 \%(6.97 \%-7.09 \%)$ (Table 2). A total of 3173 patients had eGFR $<60 \mathrm{ml} / \mathrm{min} /$ $1.73 \mathrm{~m}^{2}(20.06 \%)$ with an annual incidence of $5.89 \pm 0.12 \%$ $(5.70 \%-6.13 \%)$. Finally, 36 patients $(0.22 \%)$ had renal failure, defined as UACR $\geq 300 \mathrm{mg} / \mathrm{g}$ and $\mathrm{eGFR}<30 \mathrm{ml} / \mathrm{min} / 1.73 \mathrm{~m}^{2}$ in T2DM, with an annual incidence of $0.06 \pm 0.01 \%(0.04 \%$ $0.08 \%)$.

3.4. Statistical Analysis of any Diabetic Retinopathy. At the end of the study, all T2DM patients visited our unit and a fundus examination was carried out. We did not find any new patients with DR. We confirm, therefore, that no patient had been misdiagnosed during the screening programme. In the univariate analysis (Table 3), all studied variables are significant.

When we applied Cox's proportional regression analysis (Table 4), the variables studied in univariate analysis changed significance; thus, in the first model, current age, insulin treatment, arterial hypertension, and $\mathrm{HbAlc}$ levels sex were significant. The introduction of renal function causes new changes. The eGFR was significant in the second model $(p=0.002$, HR 1.854), but when we introduced UACR in the third model, it became less significant $(p=0.05$, HR 1.123). Finally, the inclusion of renal failure in the fourth model, defined as UACR $\geq 300 \mathrm{mg} / \mathrm{g}$ and eGFR $<$ $30 \mathrm{ml} / \mathrm{min} / 1.73$, was significant at the same level as the UACR value.

3.5. Statistical Analysis of Severe Diabetic Retinopathy Forms. Table 5 shows descriptive data of different risk factors and its significance. In STDR, current age, DM duration, HbAlc levels, UACR, and eGFR are significant in two-tailed Student's $t$-test or using one-way ANOVA analysis of variance, but creatinine levels are not significant. Similarly, in the DME study, all previously described risk factors are significant in its development. 
TABLE 1: Descriptive and frequency values of the sample.

\begin{tabular}{|c|c|c|c|c|c|}
\hline Year & $\begin{array}{l}\text { Number of subjects screened } \\
\qquad(n)\end{array}$ & $\begin{array}{l}\text { Gender: men } \\
(\%)\end{array}$ & $\begin{array}{l}\text { Mean age } \\
\text { (years) }\end{array}$ & $\begin{array}{l}\text { Diabetes duration } \\
\text { (years) }\end{array}$ & $\begin{array}{l}\text { Mean level of } \mathrm{HbA}_{1 \mathrm{c}} \% \text { mean } \pm \mathrm{SD} \\
(\min -\max )\end{array}$ \\
\hline 2007 & 4910 & $2881(57.31)$ & $64.62 \pm 12.23$ & $8.37 \pm 6.92$ & $7.37 \pm 1.48(3.9-14)$ \\
\hline 2008 & 4873 & $2802(56.16)$ & $66.27 \pm 12.32$ & $8.66 \pm 6.78$ & $6.82 \pm 1.24(4.3-12)$ \\
\hline 2009 & 5191 & $2890(54.41)$ & $65.39 \pm 12.41$ & $8.57 \pm 6.12$ & $7.02 \pm 1.7(3.8-15)$ \\
\hline 2010 & 5243 & 3007 (56.03) & $65.69 \pm 11.7$ & $8.23 \pm 6.81$ & $7.47 \pm 1.5(4.5-14.5)$ \\
\hline 2011 & 5264 & $2933(55.60)$ & $65.22 \pm 12.12$ & $8.29 \pm 6.56$ & $7.3 \pm 1.5(4-15.5)$ \\
\hline 2012 & 6193 & $3594(56.72)$ & $65.33 \pm 12.08$ & $8.23 \pm 6.82$ & $7.63 \pm 1.4(4.3-15.8)$ \\
\hline 2013 & 5494 & $3131(55.69)$ & $65.87 \pm 12.07$ & $8.28 \pm 6.11$ & $7.62 \pm 1.41(4.3-15.8)$ \\
\hline 2014 & 5983 & $3511(57.33)$ & $65.88 \pm 11.94$ & $8.34 \pm 6.83$ & $7.64 \pm 1.4(4-15.6)$ \\
\hline 2015 & 5026 & $2817(56.05)$ & $65.84 \pm 12.39$ & $8.35 \pm 6.77$ & $7.61 \pm 1.5(4.2-15)$ \\
\hline 2016 & 5423 & $3036(56)$ & $65.94 \pm 12.27$ & $8.32 \pm 6.72$ & $7.63 \pm 1.4(4.4-15.4)$ \\
\hline
\end{tabular}

Descriptive values are presented as number or mean \pm standard deviation (SD).

TABLE 2: Incidence of diabetic retinopathy and renal diabetic disease.

\begin{tabular}{ccccccc}
\hline Year & $\begin{array}{c}\text { Any-DR, } \\
n(\%)\end{array}$ & $\begin{array}{c}\text { STDR, } \\
n(\%)\end{array}$ & $\begin{array}{c}\mathrm{DME}, \\
n(\%)\end{array}$ & $\begin{array}{c}\mathrm{eGFR}<60 \mathrm{ml} / \mathrm{min} / 1.73, \\
n(\%)\end{array}$ & $\begin{array}{c}\mathrm{UACR} \geq 30 \mathrm{mg} / \mathrm{g}, \\
n(\%)\end{array}$ & $\begin{array}{c}\text { UACR } \geq 300 \mathrm{mg} / \mathrm{g} \text { and } \\
\mathrm{eGFR}<30 \mathrm{ml} / \mathrm{min} / 1.73 \mathrm{~m}{ }^{2}, n(\%)\end{array}$ \\
\hline 2007 & $390(7.94)$ & $131(2.6)$ & $104(2.00)$ & $294(5.98)$ & $343(6.98)$ & $3(0.06)$ \\
2008 & $384(7.88)$ & $125(2.5)$ & $101(2.02)$ & $290(5.95)$ & $344(7.06)$ & $2(0.04)$ \\
2009 & $411(7.06)$ & $132(2.48)$ & $112(2.11)$ & $301(5.79)$ & $363(6.99)$ & $3(0.06)$ \\
2010 & $424(8.05)$ & $134(2.49)$ & $114(2.12)$ & $309(5.89)$ & $372(7.09)$ & $4(0.07)$ \\
2011 & $407(7.73)$ & $141(2.67)$ & $110(2.08)$ & $310(5.89)$ & $432(6.97)$ & $4(0.07)$ \\
2012 & $533(8.6)$ & $170(2.68)$ & $150(2.36)$ & $353(5.70)$ & $390(7.09)$ & $4(0.06)$ \\
2013 & $489(8.9)$ & $162(2.88)$ & $135(2.40)$ & $324(5.89)$ & $419(7.01)$ & $4(0.07)$ \\
2014 & $529(8.84)$ & $174(2.84)$ & $153(2.49)$ & $357(6.13)$ & $351(6.98)$ & $5(0.08)$ \\
2015 & $415(8.25)$ & $139(2.76)$ & $122(2.42)$ & $301(5.98)$ & $385(7.09)$ & $4(0.07)$ \\
2016 & $484(8.92)$ & $144(2.65)$ & $114(2.10)$ & $314(5.79)$ & & $3(0.05)$ \\
\hline
\end{tabular}

TABLE 3: Statistical analysis at the end of the ten-year follow-up study.

\begin{tabular}{|c|c|c|c|}
\hline Variables & Category & Mean values & Univariate statistical study significance \\
\hline \multirow{2}{*}{ Age (years) } & No diabetic retinopathy & $62.53 \pm 13.63$ & \multirow{2}{*}{$p<0.001,(F=6.998)^{*}$} \\
\hline & Diabetic retinopathy & $71.94 \pm 10.56$ & \\
\hline \multirow{2}{*}{ Sex (male) } & No diabetic retinopathy & $41.50 \%$ & \multirow{2}{*}{$p<0.001$, OR $2.24(1.05-3.22)^{* *}$} \\
\hline & Diabetic retinopathy & $58.50 \%$ & \\
\hline \multirow{2}{*}{ Diabetes duration (years) } & No diabetic retinopathy & $9.36 \pm 6.58$ & \multirow{2}{*}{$p<0.001,(F=21.56)$} \\
\hline & Diabetic retinopathy & $12.18 \pm 6.21$ & \\
\hline \multirow{2}{*}{ Arterial hypertension } & No diabetic retinopathy & 49.53 & \multirow{2}{*}{$p=0.003$, OR $2.04(1.14-3.11)$} \\
\hline & Diabetic retinopathy & 50.47 & \\
\hline \multirow{2}{*}{ Insulin treatment } & No diabetic retinopathy & 18.54 & \multirow{2}{*}{$p<0.001$, OR $3.98(2.24-5.17)$} \\
\hline & Diabetic retinopathy & 51.40 & \\
\hline \multirow{2}{*}{ HbAlc (\%) } & No diabetic retinopathy & $7.69 \pm 2.69$ & \multirow{2}{*}{$p<0.001,(F=13.75)$} \\
\hline & Diabetic retinopathy & $8.07 \pm 1.76$ & \\
\hline \multirow{2}{*}{$\mathrm{eGFR}\left(\mathrm{ml} / \mathrm{min} / 1.73 \mathrm{~m}^{2}\right)$} & No diabetic retinopathy & $89.66 \pm 16.11$ & \multirow{2}{*}{$p=0.004,(F=9.10)$} \\
\hline & Diabetic retinopathy & $56.32 \pm 12.20$ & \\
\hline \multirow{2}{*}{ UACR (mg/g) } & No diabetic retinopathy & $4.82 \pm 43.00$ & \multirow{2}{*}{$p<0.001,(F=14.81)$} \\
\hline & Diabetic retinopathy & $75.30 \pm 231.26$ & \\
\hline
\end{tabular}

${ }^{*}$ Study made with two-tailed Student's $t$-test or ANOVA; F: Fisher-Snedecor distribution. ${ }^{* *}$ Study made with Chi-square; OR: odds ratio (95\% CI). 
TABLE 4: Multivariate analysis using Cox's proportional regression analysis of any-diabetic retinopathy.

\begin{tabular}{|c|c|c|c|c|}
\hline Variables & Model $1^{*}$ & Model $2^{* *}$ & Model $3^{* * *}$ & Model $4^{* * * *}$ \\
\hline \multirow{2}{*}{ Current age } & $p<0.001$ & $p<0.001$ & $p<0.001$ & $p<0.001$ \\
\hline & HR $1.136(1.084-1.224)^{\dagger}$ & HR $1.140(1.081-1.227)$ & HR $1.140(1.072-1.284)$ & HR 1.145 (1.083-1.290) \\
\hline \multirow{2}{*}{ Sex } & $p=0.065$ & $p=0.077$ & $p=0.070$ & $p=0.073$ \\
\hline & HR $0.761(0.643-0.961)$ & HR $0.822(0.668-1.060)$ & HR $0.820(0.651-1.072)$ & HR $0.834(0.644-1.015)$ \\
\hline \multirow{2}{*}{ Insulin treatment } & $p<0.001$ & $p<0.001$ & $p<0.001$ & $p<0.001$ \\
\hline & HR $1.218(1.131-1.448)$ & HR $1.302(1.188-1.506)$ & HR $1.311(1.174-1.501)$ & HR $1.302(1.178-1.545)$ \\
\hline \multirow{2}{*}{ Arterial hypertension } & $p=0.05$ & $p=0.05$ & $p=0.045$ & $p=0.049$ \\
\hline & HR 1.118 (0.985-1.788) & HR $1.121(0.907-1.340)$ & HR $1.134(1.002-1.161)$ & HR 1.367 (1.062-1.899) \\
\hline \multirow{2}{*}{$\mathrm{HbAlc}$} & $p<0.001$ & $P<0.001$ & $p<0.001$ & $p<0.001$ \\
\hline & HR 2.135 (1.893-2.408) & HR 2.089 (1.811-2.632) & HR $2.052(1.780-2.273)$ & HR 2.037 (1.806-2.297) \\
\hline \multirow{2}{*}{$\mathrm{eGFR}<60 \mathrm{ml} / \mathrm{min} / 1.73 \mathrm{~m}^{2}$} & & $p=0.002$ & $p=0.04$ & $p=0.09$ \\
\hline & & HR $1.854(1.251-4.431)$ & HR $1.223(1.098-1.201)$ & HR $1.103(0.078-1.311)$ \\
\hline \multirow{2}{*}{$\mathrm{UACR} \geq 30 \mathrm{mg} / \mathrm{g}$} & & & $p<0.001$ & $P=0.004$ \\
\hline & & & HR 1.485 (1.103-1.548) & HR 1.485 (1.092-1.465) \\
\hline \multirow{2}{*}{$\begin{array}{l}\mathrm{UACR} \geq 300 \mathrm{mg} / \mathrm{g} \text { and } \\
\mathrm{eGFR}<30 \mathrm{ml} / \mathrm{min} / 1.73 \mathrm{~m}^{2}\end{array}$} & & & & $p<0.001$ \\
\hline & & & & HR 1.998 (1.682-2.305) \\
\hline
\end{tabular}

Model $1^{*}$, Cox's analysis in which the variables of renal function are not included; model $2^{* *}$, Cox's analysis in which we include only the eGFR variable for the study of renal function; model $3^{* * *}$, Cox's analysis with eGFR and UACR as variables for the study of renal function; model $4^{* * * *}$, Cox's analysis in which we included in addition to the eGFR and the UACR, the presence of renal failure. ${ }^{\dagger}$ Hazard ratio (95\% CI).

Table 5: Descriptive data of diabetic retinopathy forms.

\begin{tabular}{lccccc}
\hline & No-DR & STDR & Significance & DME & Significance \\
\hline Current age (years) & $64.01 \pm 13.99$ & $64.05 \pm 12.27$ & $p=0.005, F=5.306$ & $64.36 \pm 12.84$ & $p=0.002, F=6.401$ \\
DM duration (years) & $8.71 \pm 6.12$ & $13.91 \pm 7.85$ & $p<0.001, F=26.141$ & $13.77 \pm 7.78$ & $p<0.001, F=25.788$ \\
HbA1c $(\%)$ & $7.33 \pm 1.76$ & $9.21 \pm 1.97$ & $p<0.001, F=29.033$ & $9.18 \pm 1.96$ & $p<0.001, F=28.867$ \\
eGFR $\left(<60 \mathrm{ml} / \mathrm{min} / 1.73 \mathrm{~m}^{2}\right)$ & $85.69 \pm 20.31$ & $73.32 \pm 24.09$ & $p=0.01, F=8.494$ & $73.17 \pm 24.20$ & $p=0.01, F=8.568$ \\
UACR $(>30 \mathrm{mg} / \mathrm{g})$ & $3.25 \pm 55.33$ & $66.68 \pm 172.56$ & $p<0.001, F=14.640$ & $67.06 \pm 173.78$ & $p<0.001, F=14.665$ \\
\hline
\end{tabular}

STDR: sight threatening diabetic retinopathy; DME: diabetic macular edema; $F=$ Fisher-Snedecor distribution.

Table 6 shows significance of different variables in Cox's analysis. In STDR patients, all risk factors are significant in model 1, according to the hazard ratio HbAlc, UACR and arterial hypertension are important risk factors. In model 2 of STDR study, we substituted eGFR $<60 \mathrm{ml} / \mathrm{min} / 1.73 \mathrm{~m}^{2}$ and UACR $\geq 30 \mathrm{mg} / \mathrm{g}$ for renal failure, defined as $\mathrm{UACR} \geq 300 \mathrm{mg} / \mathrm{g}$ and $\mathrm{eGFR}<30 \mathrm{ml} / \mathrm{min} / 1.73 \mathrm{~m}^{2}$, which become an important risk factor with a hazard ratio of 3.174, like the hazard ratio of 3.230 of HbAlc.

The study of diabetic macular edema also demonstrated that all risk factors are significant in model 1 , and HbAlc level, arterial hypertension, and UACR have the highest hazard ratio values. Also, the substitution of eGFR $<60 \mathrm{ml} / \mathrm{min} /$ $1.73 \mathrm{~m}^{2}$ and UACR $>30 \mathrm{mg} / \mathrm{g}$ for renal failure becomes an important risk factor for DME development with a hazard ratio of 3.190 like 3.194 hazard ratio of HbAlc.

3.6. Study of Survival Analysis. In this paragraph, we compared survival study made with Kaplan-Meier product-limit graph and Cox proportional hazards model. In Figures 1 and 2, we show the accumulated risk of developing diabetic retinopathy in each of the three studied categories.

Figure 1 used the Kaplan-Meier product-limit graph to evaluate the relationship between renal failure diagnosed by UACR or eGFR in each DR type. Using the plots risk function, it is evident that UACR $\geq 300 \mathrm{mg} / \mathrm{g}$ increases significantly the accumulated risk of any-DR, STDR, and DME along with DM duration. The use of eGFR $<30 \mathrm{ml} / \mathrm{min} /$ $1.73 \mathrm{~m}^{2}$ as a diagnosis of renal failure is not reliable as an indicator of an increased risk of STDR and DME, and a significant link appeared only if we studied all patients with any-DR.

Figure 2 shows the accumulated risk of DR using the Cox proportional hazards model. At the top of the figure, we observe an increased accumulated risk of development of any-DR, STDR, and DME in patients with renal failure using $\mathrm{UACR} \geq 300 \mathrm{mg} / \mathrm{g}$ as method of diagnosis. On the contrary, below that, we observe that renal failure diagnosis using the 
TABle 6: Multivariate analysis using Cox's proportional regression analysis of STDR and DME.

\begin{tabular}{|c|c|c|}
\hline & STDR & DME \\
\hline \multirow[b]{2}{*}{ Variables } & Significance & Significance \\
\hline & $\begin{array}{l}\text { Hazard ratio } \\
(95 \% \mathrm{CI})^{*}\end{array}$ & $\begin{array}{l}\text { Hazard ratio } \\
(95 \% \mathrm{CI})\end{array}$ \\
\hline \multirow[b]{2}{*}{ Current age } & $p=0.018$ & $p=0.057$ \\
\hline & $\begin{array}{c}\text { HR } 0.991 \\
(0.984-0.999)\end{array}$ & $\begin{array}{c}\text { HR } 0.993 \\
(0.986-1.000)\end{array}$ \\
\hline \multirow[b]{2}{*}{ Sex } & $p<0.001$ & $p<0.001$ \\
\hline & $\begin{array}{c}\text { HR } 0.644 \\
(0.531-0.781)\end{array}$ & $\begin{array}{c}\text { HR } 0.655 \\
(0.539-0.794)\end{array}$ \\
\hline \multirow[b]{2}{*}{ Insulin treatment } & $p=0.01$ & $p=0.01$ \\
\hline & $\begin{array}{c}\text { HR } 1.313 \\
(1.123-1.535)\end{array}$ & $\begin{array}{c}\text { HR } 1.308 \\
(1.117-1.530)\end{array}$ \\
\hline \multirow[b]{2}{*}{ Arterial hypertension } & $p<0.001$ & $p<0.001$ \\
\hline & $\begin{array}{c}\text { HR } 2.128 \\
(1.726-2.623)\end{array}$ & $\begin{array}{c}\text { HR } 2.126 \\
(1.721-2.626)\end{array}$ \\
\hline \multirow[b]{2}{*}{$\mathrm{HbAlc}$} & $p<0.001$ & $p<0.001$ \\
\hline & $\begin{array}{c}\text { HR } 3.230 \\
(2.378-4.387) \\
\end{array}$ & $\begin{array}{c}\text { HR } 3.194 \\
(2.350-4.340)\end{array}$ \\
\hline \multirow[b]{2}{*}{$\mathrm{eGFR}<60 \mathrm{ml} / \mathrm{min} / 1.73 \mathrm{~m}^{2}$} & $p=0.07$ & $p=0.09$ \\
\hline & $\begin{array}{c}\text { HR } 1.097 \\
(0.899-1.979)\end{array}$ & $\begin{array}{c}\text { HR } 1.033 \\
(0.877-1.972)\end{array}$ \\
\hline \multirow[b]{2}{*}{$\mathrm{UACR} \geq 30 \mathrm{mg} / \mathrm{g}$} & $p=0.004$ & $p=0.006$ \\
\hline & $\begin{array}{c}\text { HR } 2.099 \\
(1.163-3.072)\end{array}$ & $\begin{array}{c}\text { HR } 1.978 \\
(1.237-2.901)\end{array}$ \\
\hline \multirow{2}{*}{$\begin{array}{l}\mathrm{UACR} \geq 300 \mathrm{mg} / \mathrm{g} \text { and } \\
\mathrm{eGFR}<30 \mathrm{ml} / \mathrm{min} / 1.73 \mathrm{~m}^{2}\end{array}$} & $p<0.001$ & $p<0.001$ \\
\hline & $\begin{array}{c}\text { HR } 3.174 \\
(2.140-4.708)\end{array}$ & $\begin{array}{c}\text { HR } 3.190 \\
(2.150-4.732)\end{array}$ \\
\hline
\end{tabular}

${ }^{*}$ Hazard ratio (95\% confidence interval). STDR: sight threatening diabetic retinopathy; DME: diabetic macular edema. ${ }^{*}$ Hazard ratio $(95 \% \mathrm{CI})$.

eGFR $<30 \mathrm{ml} / \mathrm{min} / 1.73 \mathrm{~m}^{2}$ was not significant for any of three types of DR. It is interesting that using the KaplanMeier curve, any-DR had an increased accumulative risk, but in the Cox's survival analysis, after the introduction of the other risk variables (age, sex, arterial hypertension, and HbA1c), the effect disappeared and became not significant.

\section{Discussion}

The present study should be taken in the context of previous studies $[13,17]$ conducted on the same population. Incidence of any-DR at the ten-year follow-up was $28.24 \%$ with a mean annual incidence of $8.21 \pm 0.60 \%(7.06 \%-8.92 \%)$, similar to previously published data. Referable DR described as STDR had an annual incidence of $2.65 \pm 0.14 \%(2.48 \%-2.88 \%)$, and DME had an annual incidence of $2.21 \pm 0.18 \%(2 \%-$ $2.49 \%$ ); both results are similar to those of The Scottish National Diabetic Retinopathy Screening Programme [18]. A particularly interesting result from our study is that STDR incidence at ten years was 1451 patients (9.17\%), and DME affected 1214 patients (7.67\%), but only 237 patients had
STDR without DME, representing $16.33 \%$ of patients with STDR. We should take into account that STDR might be due to DME or ischemic retina secondary to severe DR and conclude that only $1.50 \%$ of patients in our study developed STDR without DME. Due to this little difference in incidence between STDR and DME patients, the two groups have similar results according to risk factors and numerical statistical data.

For diabetic nephropathy (DN), with UACR $\geq 30 \mathrm{mg} / \mathrm{g}$, there was $23.82 \%$ of patients who developed DN at the end of study, with a mean annual incidence of $7.02 \pm 0.05 \%$ (6.97\%-7.09\%). On the contrary, with eGFR $<60 \mathrm{ml} / \mathrm{min} /$ $1.73 \mathrm{~m}^{2}$, there was $20.06 \%$ patients with $\mathrm{DN}$ at the end of the study, with a mean annual incidence of $5.89 \pm 0.12 \%$ (5.70\%$6.13 \%$ ). These discrepancies can be explained because glomerular filtration rate increases in initial diabetic renal failure and then reduces in most advanced nephropathy.

Statistical analysis shows that glomerular filtration was a significant risk factor for DR and can be a predictive factor for severe DR complications, as defined in our study as STDR and DME. However, introducing UACR as a risk factor in the equation in Cox's survival analysis, the eGFR became less significant; therefore, in the development of any-DR, the HR decreases from 1.854 to 1.223 , with a change in significance from $p=0.002$ to $p=0.04$; Figures 1 and 2 clearly show this effect. When we use the Kaplan-Meier curve, the eGFR is a significant risk, but with the introduction of the other variables of age, sex, arterial hypertension, and HbAlc in the Cox's survival analysis, the effect of eGFR disappeared and UACR is the only effective risk factor. We can conclude, therefore, that UACR has greater relationship with DR development than eGFR does.

The study of STDR and DME also shows that UACR is a more significant risk factor than eGFR, despite eGFR being an important risk factor, with HR having similar values to other variables like arterial hypertension or insulin treatment.

We can explain that eGFR is a less significant risk factor than UACR in two ways. Firstly, changes in eGFR occur prior to an increase in UACR, increasing its filtration ratio in the early stage of diabetes mellitus and then reducing in advanced stages, reflecting the decline in renal function. Secondly, arteriosclerosis, which can be developed in parallel to diabetes, can decrease the glomerular filtration rate in patients with normoalbuminuria [19]. Both mechanisms can act as confounding factors in statistical results.

The greater significance of UACR in type 2 DM compared with type $1 \mathrm{DM}$ (T1DM), which we encountered in a previous study with a series of T1DM patients [17], might be explained by the different methodologies used.

In another previously published study [20], we reported low significance of microalbuminuria as risk factor for DR in T2DM, but in the same study, we encountered significant values of albuminuria $\geq 300 \mathrm{mg} / \mathrm{g}$ and $\mathrm{DR}$ development. Again, this might be due to the different methodology and the fact that the previous study was a cross-sectional feature rather than a prospective ten-year follow-up as this present study is. In previous study, we defined microalbuminuria as $30-299 \mathrm{mg} / \mathrm{g}$, and in the present study, we defined renal 

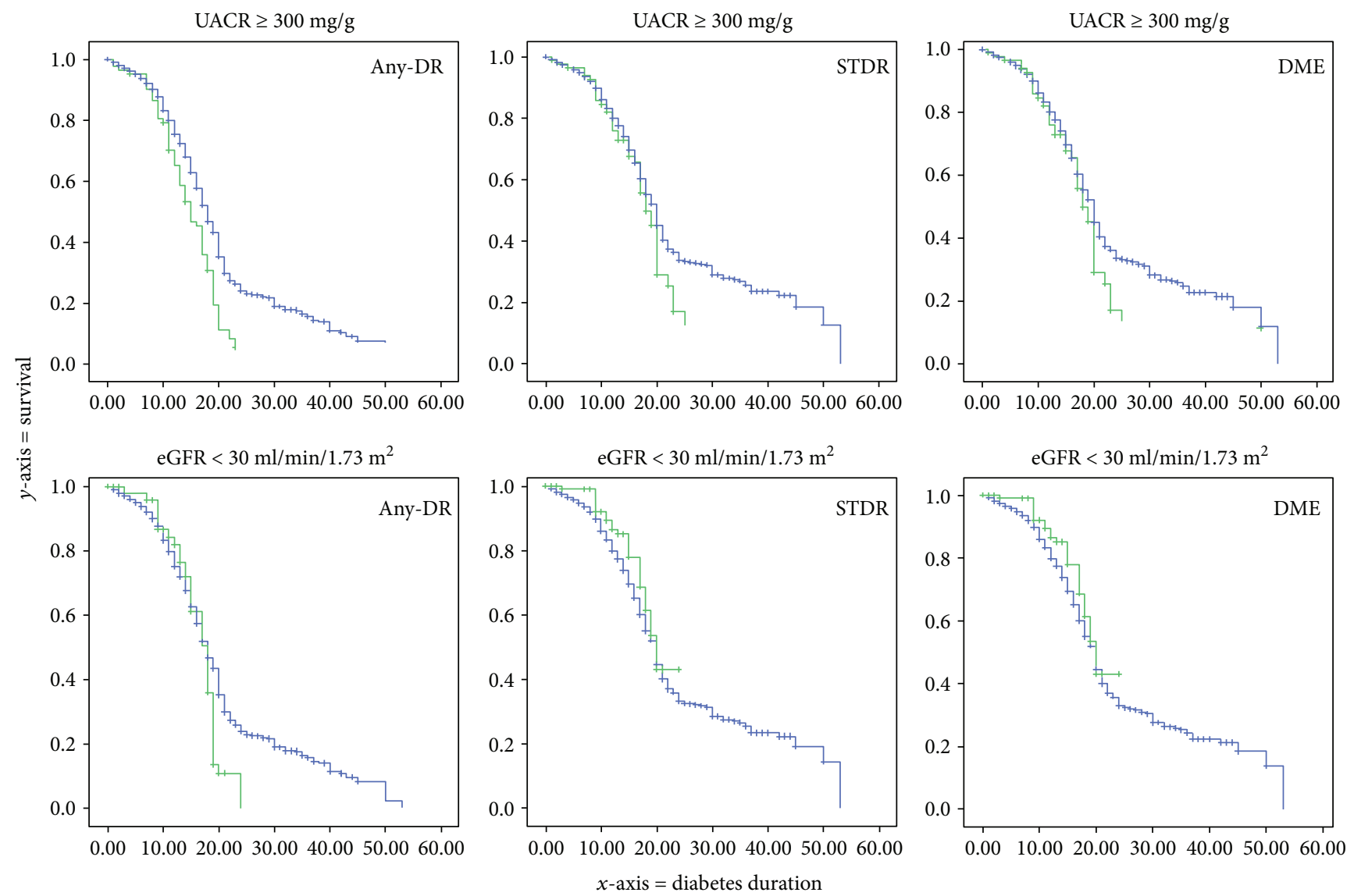

FIGURE 1: Plots of risk function of Kaplan-Meier study. The $y$-axis represents the accumulative risk to develop diabetic retinopathy, and the $x$ axis represents diabetes mellitus duration in years. The green curve represents effect of patients with renal failure as risk factor, and the blue curve patients without renal failure. At the top, there is the analysis of renal failure measured with UACR $\geq 300 \mathrm{mg} / \mathrm{g}$, and at bottom $\mathrm{eGFR}<30 \mathrm{ml} / \mathrm{min} / 1.73 \mathrm{~m}^{2}$.

nephropathy if UACR was up $30 \mathrm{mg} / \mathrm{g}$, which includes patients with microalbuminuria and macroalbuminuria.

Our results can be compared, though with caution, with similar published studies. Man et al. [21], in a case series study of 263 Caucasian patients, found a link between impaired renal function, measured by the CKD-EPI equation and severe forms of DR, but not with DME. However, as those authors said, perhaps its lower number of patients with DME can lower the significance of the results, whereas our study has a greater sample of patients (1214 patients with DME), which might highlight its significance.

$\mathrm{Wu}$ et al. [22] reported that levels of eGFR less than or equal to $99.4 \mathrm{ml} / \mathrm{min} / 1.73$ were significant for $\mathrm{DR}$ in a case-control hospital-based study. The present study considered only levels of eGFR less than $60 \mathrm{ml} / \mathrm{min} / 1.73$ as pathologic, because, as we have said, glomerular filtration increases in early stages of renal malfunction and can confound the results.

Most similar to our results are those reported by Rodríguez-Poncelas et al. [23], who carried out a crosssectional study based on 28,344 patients. They demonstrated that prevalence of DR increases in patients with $\mathrm{UACR} \geq 300 \mathrm{mg} / \mathrm{g}$ with and odds ratio of 2.0 and with a positive relation between the decrease in eGFR and STDR.
The present study also demonstrates that eGFR is a less significant risk factor than UACR.

Other studies used the modification of diet in renal disease (MDRD-4 or MDRD-IDMS) [11] to determine eGFR. López et al. [24], in a cross-sectional study, used the MDRD-4 formula. Their results are similar to ours with a significance at $p<0.001, \mathrm{OD}=2.0$, and $95 \% \mathrm{IC}=1.6-2.4$ in a clinical series of 14,266 patients. Despite MDRD only being able to be used as an alternative to the CKD-EPI equation, some publications currently estimate that the latter provides a more accurate estimate of the eGFR $[12,25,26]$.

The strengths of our study are the screening programme itself, which had included an $85.33 \%$ of T2DM patients in our HCA, and the ten-year follow-up of our T2DM population, yielding a large amount of data.

The limitations of our study are that we determined the CKD-EPI equation using creatinine data. Despite serum creatinine measurements being carried out in the same clinical laboratory, which used integrated database management system-traceable samples to minimize calibration bias, it can cause errors in determination. Also, patients with STDR, and/or DME, can be visited in hospital and bypass the screening programme, us affecting the statistical analysis. 

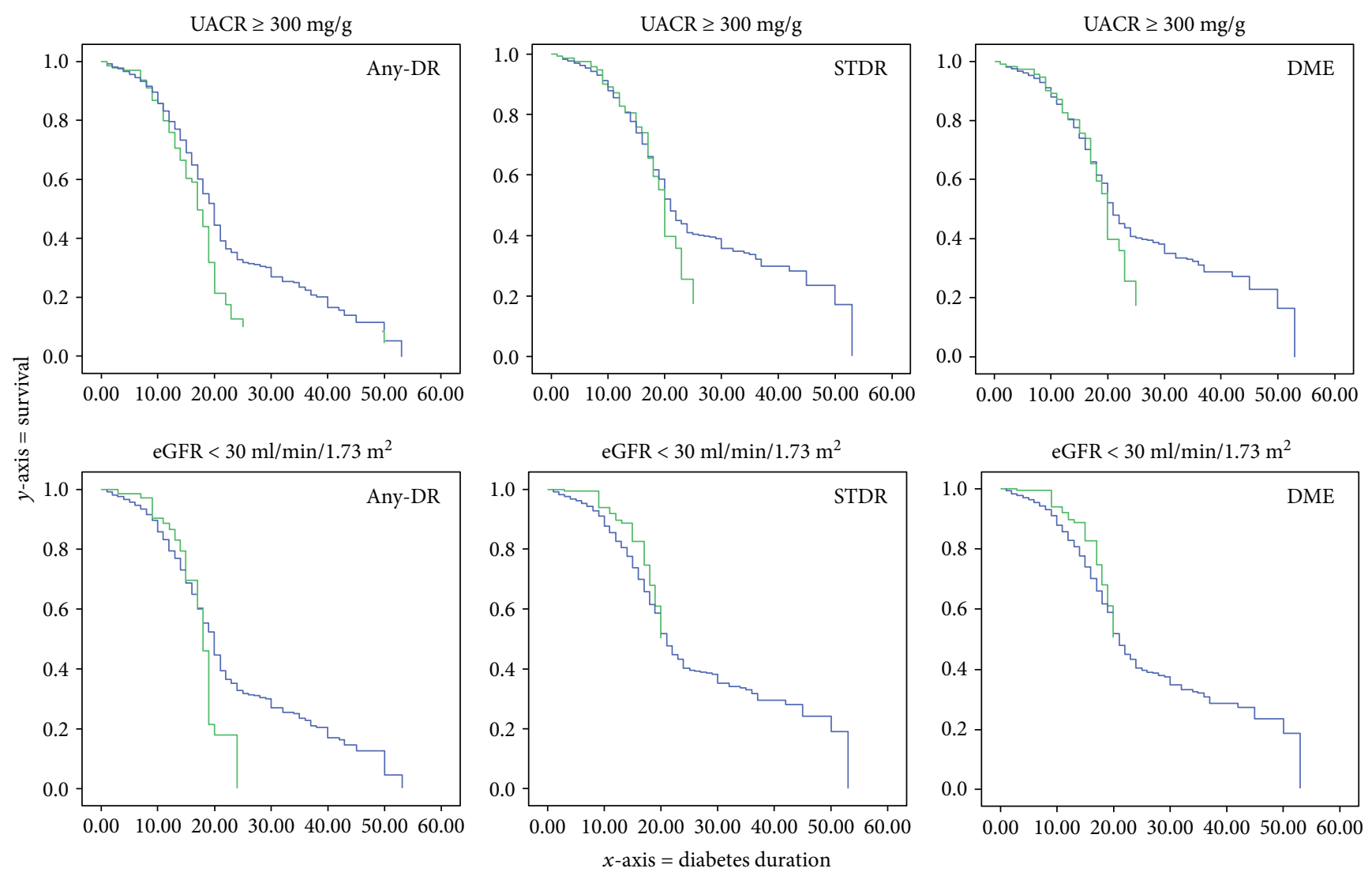

FIgURE 2: Plots of risk function of Cox study. The $y$-axis represents the accumulative risk to develop diabetic retinopathy, and the $x$-axis represents diabetes mellitus duration in years. The green curve represents the effect of patients with renal failure as a risk factor, and the blue curve patients without renal failure. At the top, there is the analysis of renal failure measured with UACR $\geq 300 \mathrm{mg} / \mathrm{g}$, and at the bottom $\mathrm{eGFR}<30 \mathrm{ml} / \mathrm{min} / 1.73 \mathrm{~m}^{2}$.

\section{Conclusions}

In conclusion, the present study has shown that UACR have higher association than eGFR with diabetic retinopathy and its severe forms. From our data, we would encourage further studies to determine the glomerular filtration rate and the relationship of DR in T2DM patients as risk factor.

\section{Disclosure}

The authors alone are responsible for the content and writing of the paper.

\section{Conflicts of Interest}

The authors report no conflicts of interest.

\section{Acknowledgments}

The authors thank all paediatricians, general practitioners, and endocrinologists in our area who have helped us to implement the new screening system using the nonmydriatic fundus camera and our camera technicians for their work and interest in the diabetes screening programme. The authors thank the GDPS network and especially Dr. Didac
Mauricio, Dr. Manel Mata-Cases, and Dr. Josep FranchNadal, without whom the authors would not have been able to develop the present CDSS. The authors also thank Mr. Phil Hoddy for his language assistance and for editing and correcting the English text. The study was approved and supported by Instituto de Salud Carlos III (IISCIII), Spain (nos. FI12/01535, June 2012, and FI15/01150, July 2015), and FEDER funds.

\section{References}

[1] International Diabetes Federation, IDF DIABETES ATLAS, Brussels, Belgium, 6TH edition, 2013, http://www.idf.org/ diabetesatlas.

[2] P. Romero-Aroca, M. Baget-Bernaldiz, J. Reyes-Torres et al., "Relationship between diabetic retinopathy, microalbuminuria and overt nephropathy, and twenty-year incidence follow-up of a sample of type 1 diabetic patients," Journal of Diabetes and its Complications, vol. 26, no. 6, pp. 506-512, 2012.

[3] P. Romero-Aroca, R. Sagarra-Aalmo, M. Baget-Bernaldiz, J. Fernandez Ballart, and I. Mendez Marin, "Prevalence and relationship between diabetic retinopathy and nephropathy, and its risk factors in the north-east of Spain, a populationbased study," Ophthalmic Epidemiology, vol. 17, no. 4, pp. 251-265, 2010. 
[4] C. M. Nzerue, K. Hewan-Lowe, P. Harvey, D. Mohammed, B. Furlong, and R. Oster, "Prevalence of non-diabetic renal disease among African-American patients with type II diabetes mellitus," Scandinavian Journal of Urology and Nephrology, vol. 34, no. 5, pp. 331-335, 2009.

[5] J. Prakash, S. D. Usha, and N. S. Kumar, "Non-diabetic renal disease in patients with type 2 diabetes mellitus," The Journal of the Association of Physicians of India, vol. 49, pp. 415-420, 2001.

[6] J. Zhou, X. Chen, Y. Xie, J. Li, N. Yamanaka, and X. Tong, “A differential diagnostic model of diabetic nephropathy and non-diabetic renal diseases," Nephrology Dialysis Transplantation, vol. 23, no. 6, pp. 1940-1945, 2008.

[7] H. H. Parving, M. A. Gall, P. Skøtt et al., "Prevalence and causes of albuminuria in non-insulin-dependent diabetic patients," Kidney International, vol. 41, no. 4, pp. 758-762, 1992.

[8] Improving Global Outcomes (KDIGO) CKD Work Group, "KDIGO clinical practice guideline for the evaluation and management of chronic kidney disease," Kidney International Supplements, vol. 3, pp. S6-308, 2013.

[9] A. Ognibene, G. Grandi, M. Lorubbio et al., "KDIGO 2012 clinical practice guideline CKD classification rules out creatinine clearance 24 hour urine collection?," Clinical Biochemistry, vol. 49, no. 1-2, pp. 85-89, 2016.

[10] A. S. Levey, J. P. Bosch, J. B. Lewis, T. Greene, N. Rogers, and D. Roth, "A more accurate method to estimate glomerular filtration rate from serum creatinine: a new prediction equation," Annals of Internal Medicine, vol. 130, no. 6, pp. 461470, 1999.

[11] A. S. Levey, L. A. Stevens, C. H. Schmid et al., "A new equation to estimate glomerular filtration rate," Annals of Internal Medicine, vol. 150, no. 9, pp. 604-612, 2009.

[12] L. A. Stevens, C. H. Schmid, T. Greene et al., "Comparative performance of the CKD epidemiology collaboration (CKDEPI) and the modification of diet in renal disease (MDRD) study equations for estimating GFR levels above $60 \mathrm{ml} / \mathrm{min} /$ 1.73 m2," American Journal of Kidney Diseases, vol. 56, no. 3, pp. 486-495, 2010.

[13] P. Romero-Aroca, S. de la Riva-Fernandez, A. Valls-Mateu, R. Sagarra-Alamo, A. Moreno-Ribas, and N. Soler, "Changes observed in diabetic retinopathy: eight-year follow-up of a Spanish population," British Journal of Ophthalmology, vol. 100, no. 10, pp. 1366-1371, 2016.

[14] P. Romero, R. Sagarra, J. Ferrer, J. Fernández-Ballart, and M. Baget, "The incorporation of family physicians in the assessment of diabetic retinopathy by non-mydriatic fundus camera," Diabetes Research and Clinical Practice, vol. 88, no. 2, pp. 184-188, 2010.

[15] S. J. Aldington, E. M. Kohner, S. Meuer, R. Klein, A. K. Sjølie, and The EURODIAB IDDM Complications Study Group, "Methodology for retinal photography and assessment of diabetic retinopathy, the EURODIAB IDDM complications study," Diabetologia, vol. 38, no. 4, pp. 437-444, 1995.

[16] ETDRS, "Detection of diabetic macular oedema study n 5 ," Ophthalmology, vol. 9, no. 96, pp. 746-751, 1989.

[17] P. Romero-Aroca, R. Navarro-Gil, A. Valls-Mateu, R. SagarraAlamo, A. Moreno-Ribas, and N. Soler, "Differences in incidence of diabetic retinopathy between type 1 and 2 diabetes mellitus: a nine-year follow-up study," British Journal of Ophthalmology, vol. 101, no. 10, pp. 1346-1351, 2017.
[18] H. C. Looker, S. O. Nyangoma, D. T. Cromie et al., "Rates of referable eye disease in the Scottish National Diabetic Retinopathy Screening Programme," British Journal of Ophthalmology, vol. 98, no. 6, pp. 790-795, 2014.

[19] A. Tone, K. Shikata, M. Matsuda et al., "Clinical features of non-diabetic renal diseases in patients with type 2 diabetes," Diabetes Research and Clinical Practice, vol. 69, no. 3, pp. 237-242, 2005.

[20] R. A. Pedro, S. A. Ramon, B. B. Marc, F. B. Juan, and M. M. Isabel, "Prevalence and relationship between diabetic retinopathy and nephropathy, and its risk factors in the north-east of Spain, a population-based study," Ophthalmic Epidemiology, vol. 17, no. 4, pp. 251-265, 2010.

[21] R. E. Man, M. B. Sasongko, J. J. Wang et al., "The association of estimated glomerular filtration rate with diabetic retinopathy and macular edema," Investigative Opthalmology \& Visual Science, vol. 56, no. 8, pp. 4810-4816, 2015.

[22] J. Wu, J. Geng, L. Liu, W. Teng, L. Liu, and L. Chen, "The relationship between estimated glomerular filtration rate and diabetic retinopathy," Journal of Ophthalmology, vol. 2015, 8 pages, 2015.

[23] A. Rodríguez-Poncelas, X. Mundet-Tudurí, S. MiravetJiménez et al., "Chronic kidney disease and diabetic retinopathy in patients with type 2 diabetes," PLoS One, vol. 11, article e0149448, no. 2, 2016.

[24] M. López, F. Xavier Cos, F. Álvarez-Guisasola, and E. Fuster, "Prevalence of diabetic retinopathy and its relationship with glomerular filtration rate and other risk factors in patients with type 2 diabetes mellitus in spain. DM2 HOPE study," Journal of Clinical \& Translational Endocrinology, vol. 9, pp. 61-65, 2017.

[25] L. A. Stevens, M. A. Claybon, C. H. Schmid et al., "Evaluation of the chronic kidney disease epidemiology collaboration equation for estimating the glomerular filtration rate in multiple ethnicities," Kidney International, vol. 79, no. 5, pp. 555$562,2011$.

[26] J. H. Ix, C. L. Wassel, L. A. Stevens et al., "Equations to estimate creatinine excretion rate: the CKD epidemiology collaboration," Clinical Journal of the American Society of Nephrology, vol. 6, no. 1, pp. 184-191, 2011. 


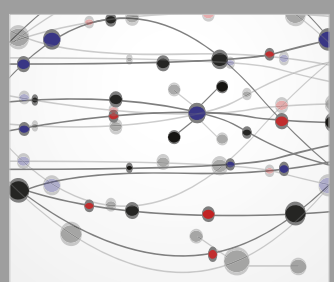

The Scientific World Journal
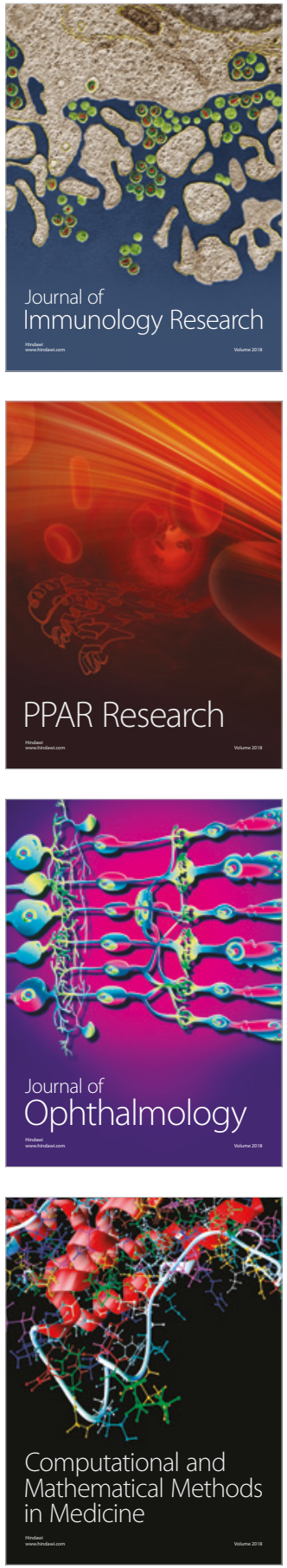

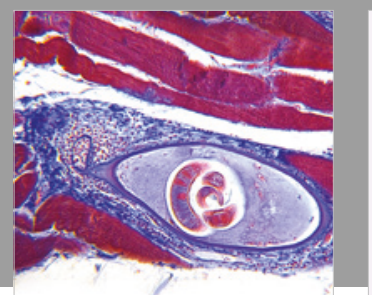

Gastroenterology Research and Practice

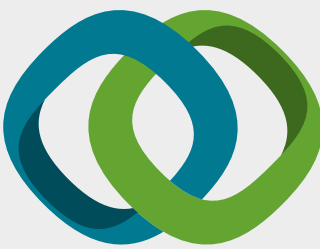

\section{Hindawi}

Submit your manuscripts at

www.hindawi.com
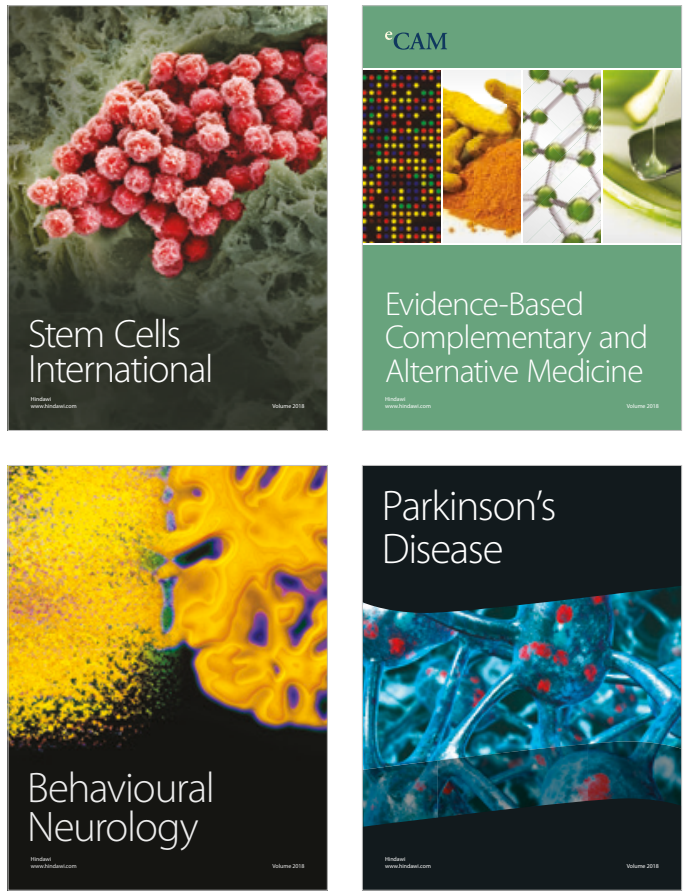

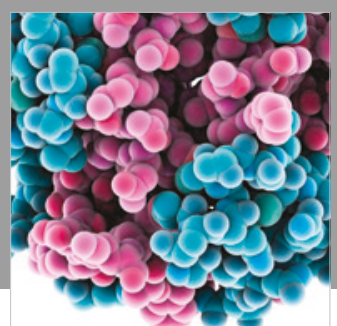

ournal of

Diabetes Research

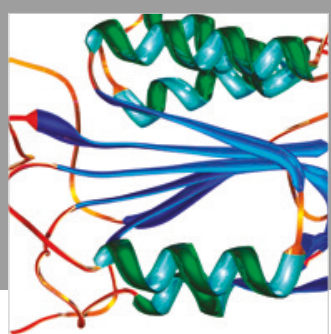

Disease Markers
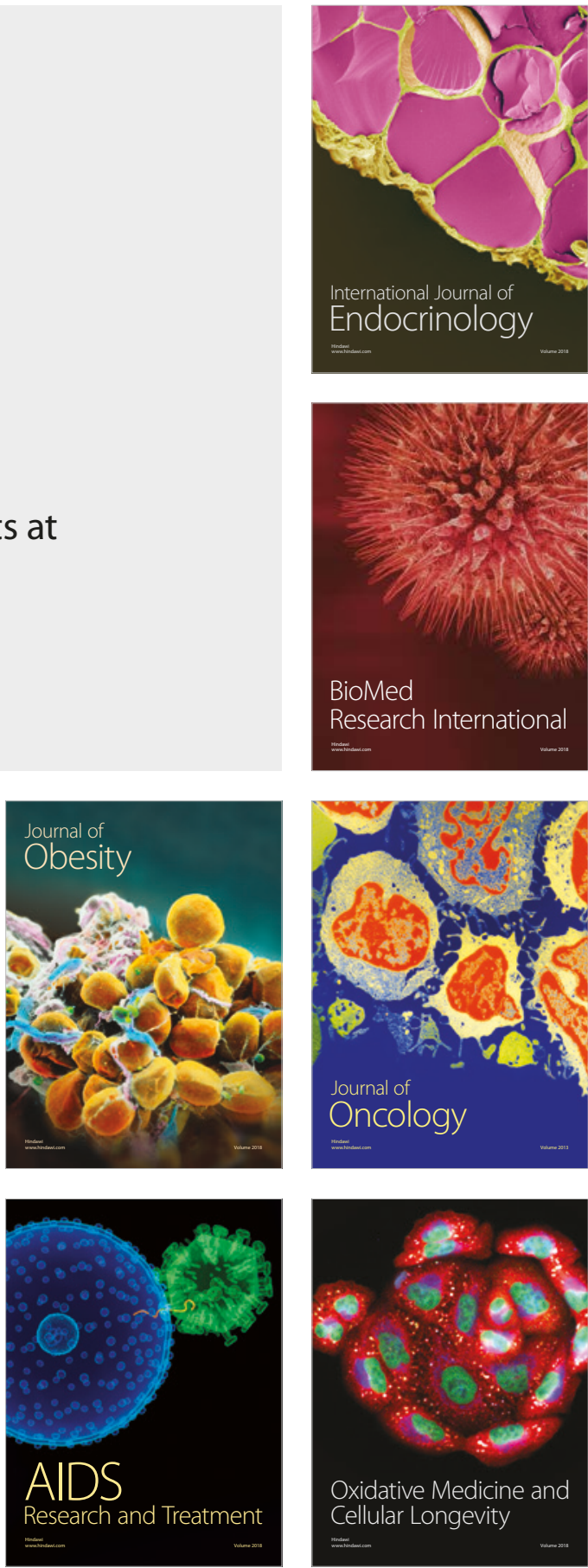